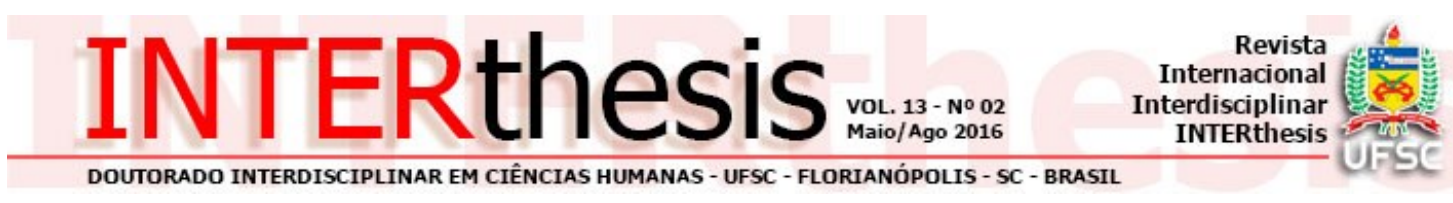

\title{
CARACTERÍSTICAS DO ESPAÇO ARQUITETÔNICO FACILITADORAS DO ENSINO E APRENDIZAGEM
}

\section{Resumo:}

Maria do Carmo de Lima Bezerra ${ }^{1}$ Mona Lisa Lobo de Souza Choas ${ }^{2}$

O artigo discute a relevância do espaço arquitetônico como facilitador do processo de ensino e aprendizagem. Utiliza metodologia analítica fundamentada na pesquisa bibliográfica para conhecer a visão das áreas da arquitetura e da pedagogia sobre o tema, e identificar atributos espaciais relevantes para facilitar a educação. A pesquisa demonstrou que existem recorrências apontando os campos disciplinares do conforto ambiental, ergonomia e psicologia ambiental, os quais foram objeto dessa investigação conceitual quanto aos impactos positivos e negativos de cada atributo, dos referidos campos disciplinares, sobre os espaços escolares. Como resultado é apresentado um Quadro de Referência de atributos, suas possibilidades de espacialização e a relevância para o ensino e aprendizagem a ser utilizado como apoio à formulação de programas de necessidades arquitetônicas, ou seja: na primeira etapa do processo de elaboração de um projeto de arquitetura.

Palavras-chave: Aprendizagem. Arquitetura. Escola. Espaço. Projeto.

\section{INTRODUÇÃO}

A discussão do papel do espaço arquitetônico no desempenho das funções do ensino e da aprendizagem de nível superior tem sido objeto de poucas reflexões em oposição ao ensino infantil onde se concentra a maioria dos estudos sobre o tema. Associar e extrapolar as relações válidas para os diferentes níveis de ensino constitui o desafio do estudo que se relata nesse artigo.

Uma constante entre os autores pesquisados é a referência à enorme distância entre arquitetos e pedagogos no momento de definição do programa de necessidades para construção de uma escola. Apesar de não ficar claro se, em algum momento na história, a relação entre a forma de projetar escolas considerou as metodologias de ensino os estudos pesquisados destacam, o que ocorre hoje

\footnotetext{
1 Doutora em Estruturas Ambientais Urbanas pela Universidade de São Paulo. Pós-doutorado na Cornell University, Estados Unidos. Professora da Universidade de Brasília atuando nos Programas de mestrado e doutorado em Arquitetura e Urbanismo. Membro do Conselho de Planejamento Territorial e Urbano do Distrito Federal, DF, Brasil E-mail: macarmo@unb.br

2 Doutoranda em Arquitetura e Urbanismo pela Universidade de Brasília, arquiteta pela mesma universidade no Distrito Federal, DF, Brasil E-mail: arqmona05@gmail.com
} 
quando predomina a padronização das escolas como resposta a um ideário arquitetônico do movimento modernista.

A observação corrente é a de que os edifícios escolares modernos deixam sua marca na paisagem urbana, porém nem sempre respondem às funções a que se destinam. O que predomina na prática de concepção de espaços arquitetônicos escolares é a busca pela padronização. Buffa \& Almeida Pinto (2002) destacam que, a partir dos anos de 1960, o diálogo entre educadores e arquitetos na definição do projeto do edifício escolar tornou-se praticamente inexistente, e o distanciamento dos profissionais ligados às áreas pedagógicas permitiu o surgimento de certas idiossincrasias na articulação dos espaços escolares.

Assim, se por um lado, os exteriores dos edifícios tornaram-se imponentes em suas formas geométricas simples, esculpidas no concreto aparente, transparecendo toda plenitude modernista, por outro lado, o espaço interior passou a não obedecer nenhuma política pedagógica definida que poderia orientar o projeto de edifícios.

Mais do que os materiais e a forma externa, o que está em jogo nessa relação é a busca de espaços que atendam às atividades que irão se desenvolver, sem ter em mente modelo predefinido, mas sim de investigar as demandas para encontrar a forma que represente as necessidades da escola, do hospital, ou da fábrica, que longe estão de serem semelhantes.

O programa de necessidades é a primeira etapa na elaboração de um projeto de arquitetura e resulta no denominado Estudo Preliminar. Entende-se que nessa etapa devem interagir todas as informações sobre as características referentes às atividades que ocorrerão no edifício tendo em conta que para cada atividade deve existir um conjunto de atributos espaciais, que podem facilitar, ou não, seu desempenho.

Os arquitetos tendem a cumprir essa etapa de forma muito intuitiva com entrevistas com usuários do futuro edifício, e possuem dificuldades em traduzir os atributos espaciais necessários ao desempenho de suas atividades, e de estabelecer as superfícies necessárias para acomodar as atividades para as quais o edifício está sendo projetado.

Entretanto, o currículo (listagem das disciplinas) e o método de ensino de uma escola devem influenciar o projeto dos ambientes, que podem potencializar e 
facilitar o processo educacional (MCDONALD, 1996). Segundo Pauly (1991) cada currículo e cada metodologia demandam espaços específicos, influenciando cada ambiente em suas características arquitetônicas, que incluem o tamanho dos espaços, a disposição do mobiliário, a infraestrutura e os equipamentos necessários e o próprio estilo arquitetônico da edificação escolar.

É importante o entendimento das atividades educacionais, suas condições de localização no espaço e na sociedade para evitar um desencontro de propostas, onde os edifícios não atendem aos aspectos pedagógicos da política educacional e de inserção urbana das escolas. Essa interface é extremamente complexa, porém, fundamental na diretriz dos programas construtivos das novas escolas.

Assim, os estudos que ofereçam elementos espaciais que possam facilitar o ensino e a aprendizagem durante a etapa de elaboração do programa de necessidades podem ser uma ferramenta de objetividade e assertividade na elaboração do espaço escolar.

\section{VISÕES SOBRE O ESPAÇO ESCOLAR NO ÂMBITO DA ARQUITETURA E DA PEDAGOGIA.}

O pedagogo Anísio Teixeira (1960) expõe sua visão sobre o espaço escolar quando diz que "nenhum outro elemento é tão fundamental, no complexo da situação educacional, depois do professor, como o prédio e suas instalações". Vai ao encontro dessa ideia o arquiteto Paulo Sophia (2007) quando, em entrevista ao Dossiê Arquitetura da Revista Educação, define que fazer arquitetura é entender um problema, refletir, planejar, muito mais que desenhar.

O reconhecimento das necessidades específicas dos espaços e sua reinterpretação no momento de projetar exigem do arquiteto um conhecimento da realidade que deve ir além das informações técnico-construtivas, uma vez que sua atuação envolve um contínuo processo de tomada de decisões em resposta aos problemas concretos, relacionados ao desempenho do tipo de atividade que se desenvolve no espaço.

No que se refere ao entendimento do que seja espaço arquitetônico, Lúcio Costa (1995) oferece uma boa relação ente forma e função ao enfatiza ser a "arquitetura antes de tudo construção, mas construção concebida com o propósito 
primordial de ordenar e organizar o espaço para determinada finalidade e visando a determinada intenção, revelando-se igualmente arte plástica, porquanto nos inumeráveis problemas com que se defronta o arquiteto, desde a germinação do projeto até a conclusão efetiva da obra, há sempre, para cada caso específico, certa margem final de opção entre os limites - máximo e mínimo - determinados pelo cálculo, preconizados pela técnica, condicionados pelo meio, reclamados pela função ou impostos pelo programa”.

Apesar dessa visão de um dos responsáveis pela formação de várias gerações de arquitetos brasileiros, têm sido reduzidos os estudos no Brasil que procuram definir metodologias objetivas de projeto para construção dessas relações. Assim, a utilização do trabalho do arquiteto Chistopher Alexander (1979) é uma referência inevitável, enquanto estudo de relações de maior objetividade entre as necessidades das funções que ocorreram no espaço e a proposição dos projetos arquitetônicos.

Em sua busca metodológica de projeto, expressa em suas obras mais importantes (Alexander,1979; Alexander, Ishikawa; e Silvestein, 1977) ele extrai configurações que considera essenciais para tornar o ambiente humanizado, as quais ele denominou padrões (patterns), que seriam parâmetros de projeto a serem ponderados, especialmente durante a elaboração do programa de necessidade. Os "patterns" não são modelos a serem copiados, mas relações a serem observadas.

Segundo Kowaltowski, 2011 os "patterns" expressam a percepção das necessidades humanas no ambiente construído por meio da descrição da relação "se" e "então", auxiliada por desenhos e fotografias.

Nas palavras de Nair e Fielding (2005) a aplicação do método dos padrões abarca quatro campos da experiência humana: espacial, psicológico, fisiológico e comportamental; e a partir desses campos os pesquisadores desenvolveram diretrizes para os ambientais escolares, como se vê no Quadro 1.

Quadro 1. Padrões (patterns) de Projeto para a escola

\begin{tabular}{|c|c|c|}
\hline PADRÕES & IMPORTÂNCIA & DIRETRIZES DOS AMBIENTES \\
\hline $\begin{array}{l}1 . \\
\text { Salas de aula, } \\
\text { ambientes de } \\
\text { ensino e } \\
\text { comunidades } \\
\text { pequenas de } \\
\text { aprendizado: }\end{array}$ & $\begin{array}{l}\text { Análise sobre o tipo de ambiente } \\
\text { considerado adequado pela escola, para } \\
\text { uma sala de aula. } \\
\text { Isso significa relacionar o aspecto físico do } \\
\text { ambiente ao currículo escolar e à sua } \\
\text { filosofia de ensino. } \\
\text { As novas metodologias de ensino } \\
\text { demonstram que os ambientes de ensino } \\
\text { atuais devem possibilitar maior variedade de }\end{array}$ & $\begin{array}{l}\text { - } \quad \text { livre movimentação de alunos; } \\
\text { - } \quad \text { os alunos podem desenvolver atividades com } \\
\text { equipamentos e objetos; } \\
\text { - } \quad \text { layouts para diferentes tipos e atividades } \\
\text { individuais; } \\
\text { - } \quad \text { alunos tem a liberdade de escolher atividades e } \\
\text { lugares para seu desenvolvimento; } \\
\text { - } \quad \text { várias metodologias pedagógicas podem ser } \\
\text { - } \quad \text { livre trânsicadas nos espaços; } \\
\end{array}$ \\
\hline
\end{tabular}




\begin{tabular}{|c|c|}
\hline PADRÕES & IMPORTÂNCIA \\
\hline & configurações de aprendizagem. \\
\hline $\begin{array}{l}2 . \\
\text { Entrada } \\
\text { convidativa }\end{array}$ & $\begin{array}{l}\text { Dada ao projeto da área de entrada da } \\
\text { escola. Ela deve "convidar" os alunos a } \\
\text { entrarem e demonstrar que são bem-vindos. } \\
\text { Esses aspectos têm de estar integrados } \\
\text { com as necessidades de proteção e de } \\
\text { segurança e com a separação dos espaços } \\
\text { de acesso público daquelas áreas restritas } \\
\text { aos alunos. }\end{array}$ \\
\hline
\end{tabular}

3.

Espaços de Previsão, no projeto, de espaços de exposição dos exposição de trabalhos de alunos, para que trabalhos dos a população estudantil se sinta valorizada alunos

- área de circulação minimizada.

- $\quad$ projeto com identidade própria que distingue a escola e o seu significado na comunidade;

- cobertura ampla para acomodar a população da escola na entrada e na saída escolar;

- espaço de transição amplo, coberto e conectado à área administrativa da escola e às áreas predominantemente utilizadas pela comunidade;

- área de entrada com vitrines para exposição de trabalhos de alunos e outras exposições.

- $\quad$ as exposições devem ser presentes em várias áreas: entrada, nos corredores, nas salas de aula etc.

- o espaço deve ter superfícies verticais (quadros, pôsteres, desenhos) e horizontais (maquetes, objetos tridimensionais, equipamentos, como microscópios ou outros) e podem ser utilizadas como elementos decorativos espalhados por todo o edifício escolar.

\section{4.}

Espaço

individual para

armazena-

mento

materiais:
Espaço pessoal de armazenamento dos materiais para cada aluno. Todo aluno necessita de lugar seguro de referência e de de guarda de material pessoal.
5. Laboratórios de ciências e artes
Espaços onde geralmente o aprendizado acontece através da prática e da aplicação dos conceitos aprendidos.
- a área de armários individuais deve ficar próxima à área de estudo e pesquisa ou à sala de aula (quando fixa) do aluno;

- o ideal é que cada aluno tenha sua própria mesa para que haja possibilidade de personalização.

- laboratório ativo: layout flexível;

- área expositiva: espaço onde trabalhos completos ou em andamento são expostos como evidência dos trabalhos desenvolvidos no laboratório;

- áreas destinadas a trabalhos mais "sujos": espaços que envolvem materiais como água ou tinta.

- áreas destinadas a intervalos nas atividades manuais, onde podem se realizar debates e tomar algumas decisões sobre os projetos que estão em desenvolvimento, de modo informal.

- áreas destinadas a estoque e guarda de equipamentos, materiais, etc.

- $\quad$ amplo espaço para exposição de atividades artísticas dos alunos;

- muitos lugares na escola para apresentações espontâneas (pequenos palcos e degraus para plateia);

- teatro completo conectado a um espaço multiuso (interior e exterior), que pode funcionar como um lugar de grande público;

Essas áreas devem dar oportunidades para Arte, música e os alunos inserirem objetos artísticos no atuação prédio escolar e participarem, junto com artistas locais, da criação de obras de arte.

- área para alunos construírem cenários, figurinos , programas de rádio, etc.;

- gráfica para publicar um jornal da escola editado pelos alunos:

- área e sala para atividades multimídia(apresentações teatrais e música);

- áreas externas para apresentações musicais ou de teatro que possam ser usadas também como sala de aula (providenciar sombra em clima tropical);

- $\quad$ atividades realizadas nos espaços internos incluindo caminhadas, natação recreativa e treinamento com pesos;

- áreas para a realização de ginástica dos alunos devem parecer com as

- academias ( incentivar hábitos saudáveis e qualidade de vida deles);

- áreas tradicionais de esporte devem permitir usos mais variados:

- espaços escolares projetados para possibilitar a integração dos bons hábitos alimentares com a prática de exercícios físicos para a manutenção de uma vida saudável. (incluir cozinhas e cantinas como espaços educacionais de disciplinas que abordam saúde, alimentação e bem estar). realizadas continuamente na vida pósacadêmica dos alunos.

8. Um dos problemas da maioria das escolas é Áreas casuais a maneira como é tratada a alimentação dos

- a escolha do horário da alimentação pelo aluno, com 


\begin{tabular}{ll}
\hline \multicolumn{1}{c}{ PADRÕES } & \multicolumn{1}{c}{ IMPORTÂNCIA } \\
\hline de alimentação & alunos. \\
& $\begin{array}{l}\text { As refeições acontecem dentro de regras } \\
\text { rígidas em refeitório geralmente implantado }\end{array}$ \\
& em ambientes grandes, barulhentos, com \\
& móveis desconfortáveis e de caráter \\
& institucional. \\
& Os alunos fazem fila e o cardápio é pouco \\
& variado. \\
& Tanto na apresentação da comida como \\
& também no ambiente físico do refeitório ou \\
& da cantina escolar falta à preocupação com \\
& o elemento estético.
\end{tabular}

$\begin{array}{ll}9 . & \text { na escola. } \\ \text { Transparência } & \text { Cria um sentido de abertura e acesso livre }\end{array}$ às dependências da escola, mas sem comprometer ou interferir acusticamente com as atividades didáticas do espaço escolar.

O conceito da transparência é de extrema importância na arquitetura escolar.

Ele deve transmitir a ideia de que educação e aprendizagem são visíveis e celebrados

\section{DIRETRIZES DOS AMBIENTES}

serviços de almoço oferecidos em horas mais flexíveis e pequenas refeições disponíveis durante o horário escolar;

- fornecimento das refeições em "cafés" menores, mais íntimos do que os grandes refeitórios escolares e refeitórios menores, em lugares mais agradáveis;

- áreas de refeições com vista para jardins e móveis mais descontraídos com variação de mesas, cadeiras e disposição até de sofá e mesa de centro:

- ambientação dos espaços de alimentação escolhida pelos alunos e periodicamente renovada;

- $\quad$ participação dos alunos na preparação e distribuição da comida e na preparação do cardápio, com oferecimento de variedade de pratos para melhor atender gostos individuais de alunos;

- cafés pensados como empreendimentos dos alunos para ensinar administração financeira e planejamento estratégico de empresas de alimentação;

- $\quad$ áreas de alimentação (cafés) abertas durante o horário escolar, podendo servir também como espaços para estudos individuais ou em grupo.

- área administrativa da escola aberta, em um espaço convidativo, para que os funcionários consigam monitorar a entrada e a área aberta junto à entrada onde alunos podem estudar livremente;

- área administrativa com acesso visual a áreas de socialização e estudo individual ou em grupo dos alunos;

- $\quad$ salas de aula com visibilidade para áreas de estudos adjacentes, permitindo seu o monitoramento pelos professores;

- $\quad$ corredores com luz natural, vistas (interessantes) ocasionais para o exterior, ao longo do percurso, para evitar a sensação de confinamento e monotonia, com áreas de estudo com aberturas para os corredores, permitindo a supervisão natural destes espaços.

Como as atividades escolares acontecem predominantemente em espaços internos é importante oferecer um horizonte externo

10.

Vistas

interiores

exteriores

maior para salas de aula, laboratorios, areas de estudo, de socialização e de e alimentação.

Além de vistas a paisagens externas interessantes, o projeto deve também oferecer vistas internas instigantes

A tecnologia faz parte da vida humana e não pode ser mais ignorada no ambiente escolar.

11. A tecnologia é usada para se comunicar, Tecnologia distribuída descobrir o mundo, jogar, brincar, colaborar com outros, escrever, criar objetos, ler e organizar a própria vida.

Por esta razão, não pode mais ser restrita a um laboratório ou sala de computador:

12. Conexão espaço externo interno
O ser humano é geneticamente um animal do ar livre e as crianças, mais do que os adultos, têm uma relação forte com o ambiente externo.

e O projeto de uma escola deve propiciar ampla possibilidade para os alunos usarem o ambiente externo.
- $\quad$ as vistas são importantes para descansar a visão que foca longamente em livros, computadores etc., campo de visão muito próximo.

- recomenda-se a possibilidade de ter um campo de visão de no mínimo 20 metros de distância;

- deve estar presente em grande parte dos espaços escolares;

- a área da escola deve ter um sistema wireless, para permitir o acesso à informação em toda extensão da escola;

- a escola deve fornecer lugares para trilhas, circuito de corrida, horta e pomar como extensão dos ambientes internos da escola;

- $\quad$ as conexões entre interior e exterior dos ambientes da escola devem ser otimizadas ao máximo, através de vistas, terraços, salas de aula ao ar livre, cantos para sentar, ler, discutir, usar laptop etc.;

- $\quad$ as conexões entre interior e exterior devem ser diretas, sem barreiras, permitindo o livre acesso a cada área, quando convém para as atividades didáticas;

- as áreas externas conectadas às salas de aula também permitem atividades diferenciadas não adequadas em espaços internos, tais como grandes 


\begin{tabular}{|c|c|c|}
\hline PADRÕES & IMPORTÂNCIA & DIRETRIZES DOS AMBIENTES \\
\hline & & $\begin{array}{l}\text { projetos e projetos que criam sujeira, com água, } \\
\text { terra etc.; }\end{array}$ \\
\hline $\begin{array}{l}13 . \\
\text { Mobiliário } \\
\text { macio para } \\
\text { sentar }\end{array}$ & $\begin{array}{l}\text { A maior queixa de alunos em avaliações } \\
\text { pós-ocupação em escolas é sobre o } \\
\text { mobiliário, em especial as cadeiras, sempre } \\
\text { consideradas duras. } \\
\text { Os alunos sentem falta de sofás, poltronas, } \\
\text { almofadas etc., normais em outros } \\
\text { ambientes (lar, escritórios etc.). } \\
\text { Como o aluno passa muitas horas sentado, } \\
\text { a ergonomia e a maciez das superfícies } \\
\text { para sentar devem ser consideradas. }\end{array}$ & $\begin{array}{l}\text { - todas as cadeiras escolares devem ser estofadas; } \\
\text { providenciar uma variedade de móveis para sentar, } \\
\text { permitindo mudanças de postura durante uma aula; } \\
\text { na área da escola assentos macios devem ser } \\
\text { distribuídos, permitindo discussões agradáveis } \\
\text { espontâneas. }\end{array}$ \\
\hline $\begin{array}{l}14 . \\
\text { Espaços } \\
\text { flexíveis }\end{array}$ & $\begin{array}{l}\text { Atualmente, existe uma variedade grande de } \\
\text { maneiras de aprender e, portanto de } \\
\text { ensinar. Esta variedade demanda } \\
\text { diferenciação de arranjos físicos, o que } \\
\text { significa importância para a flexibilidade dos } \\
\text { espaços construídos. } \\
\text { Entretanto, a flexibilidade não pode ser } \\
\text { resolvida com ambientes neutros, que, na } \\
\text { teoria, acomodam qualquer ou todas as } \\
\text { atividades previstas. } \\
\text { Espaços multifuncionais são importantes, } \\
\text { mas necessitam arranjos que sinalizam seus } \\
\text { usos. } \\
\text { O importante para a flexibilidade nos } \\
\text { ambientes de aula é a acomodação de } \\
\text { grande número de atividades diversificadas. } \\
\text { Flexibilidade depende da possibilidade de } \\
\text { expansão das áreas construídas, de } \\
\text { modificação de layout e modificação das } \\
\text { funções. }\end{array}$ & 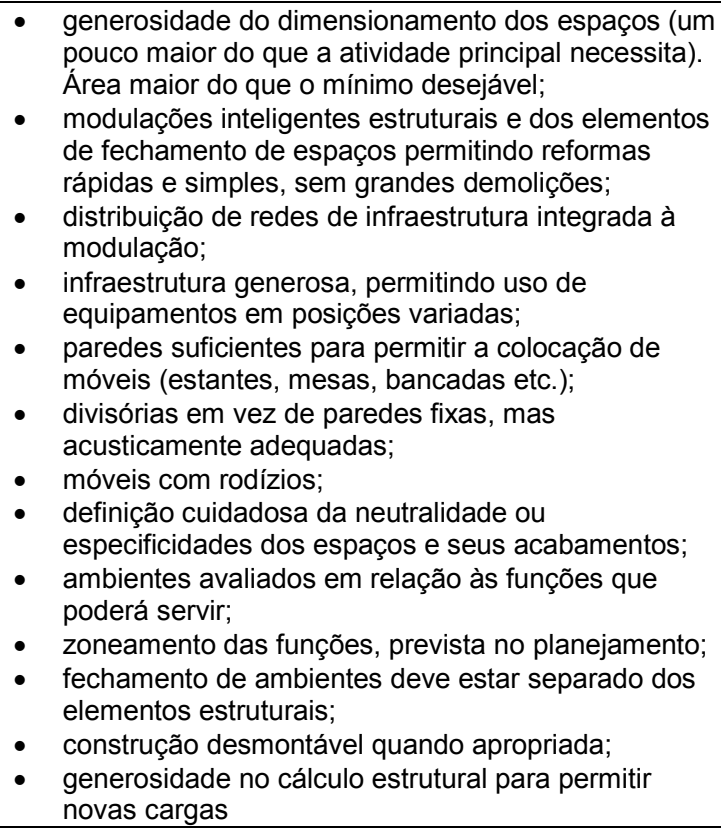 \\
\hline $\begin{array}{l}15 . \\
\text { Campfire }\end{array}$ & $\begin{array}{l}\text { Metáfora que relaciona a maneira de se } \\
\text { ensinar através de um especialista ou de um } \\
\text { contador de histórias, que compartilha seu } \\
\text { conhecimento com os alunos, ou seja, a } \\
\text { discussão em torno de uma figura central e } \\
\text { superior. }\end{array}$ & $\begin{array}{l}\text { - uma área um pouco mais elevada (tablado); } \\
\text { - } \quad \text { a acústica deve levar em conta a reflexão da fala do } \\
\text { palestrante no pódio; } \\
\text { - existem duas modalidades de palestras: formal e } \\
\text { informal e o espaço deve ter a possibilidade de } \\
\text { arranjos dos móveis para esses dois usos; } \\
\text { - equipamentos de projeção de última geração devem } \\
\text { estar disponíveis e em posição de boa visibilidade } \\
\text { do grupo de alunos. É importante pensar nas } \\
\text { necessidades do ensino a distância; } \\
\text { - o escurecimento do espaço com cortinas, ou outros } \\
\text { dispositivos de bloquear luzes de ambientes } \\
\text { adjacentes deve ser fácil e rápido para permitir a } \\
\text { apresentação de slides ou filmes; } \\
\text { no tablado, é importante ter apoio para laptop com } \\
\text { acesso à Internet e equipamento de acesso remoto; } \\
\text { deve haver equipamento de ampliação da fala } \\
\text { (sistema de som wireless) de palestrante. }\end{array}$ \\
\hline $\begin{array}{l}16 . \\
\text { Watering hole } \\
\text { space }\end{array}$ & $\begin{array}{l}\text { Espaços de aprendizado mais informais, } \\
\text { pois se sabe da importância do } \\
\text { desenvolvimento de habilidades relativas ao } \\
\text { discurso social e ao aprendizado } \\
\text { colaborativo na formação dos estudantes. } \\
\text { Watering hole space distancia-se do modelo } \\
\text { de ensino e controle tradicional, que } \\
\text { desencoraja a interação entre os alunos, } \\
\text { pois a entende como fonte de distração e } \\
\text { falta de disciplina. }\end{array}$ & $\begin{array}{l}\text { para o desenvolvimento desse tipo de atividade, } \\
\text { além de serem reservadas áreas específicas para o } \\
\text { desenvolvimento de tais atividades podem ser } \\
\text { utilizados os espaços de circulação, com nichos e } \\
\text { mesas para trabalhos em grupo }\end{array}$ \\
\hline $\begin{array}{l}17 . \\
\text { Cave space }\end{array}$ & $\begin{array}{l}\text { Metáfora que relaciona o espaço de uma } \\
\text { caverna ao espaço individual, quieto, de } \\
\text { reflexão e estudo, também importante para } \\
\text { o aprendizado. }\end{array}$ & $\begin{array}{l}\text { - esse tipo de espaço acaba sendo sempre entendido } \\
\text { como as áreas de biblioteca. Não necessita de } \\
\text { silêncio absoluto, podendo ocorrer em espaços } \\
\text { externos, cafés ou outros ambientes com mobiliários } \\
\text { que permitam esse tipo de uso. }\end{array}$ \\
\hline
\end{tabular}




\begin{tabular}{|c|c|c|}
\hline PADRÕES & IMPORTÂNCIA & DIRETRIZES DOS AMBIENTES \\
\hline $\begin{array}{l}18 . \\
\text { Projeto para } \\
\text { inteligências } \\
\text { múltiplas }\end{array}$ & $\begin{array}{l}\text { Existem diversos tipos de inteligência por } \\
\text { explorar nas escolas, para cada aluno } \\
\text { descobrir suas potencialidades, } \\
\text { desenvolvendo as mais frágeis e } \\
\text { expressando as mais fortes. } \\
\text { Cada inteligência -linguística, lógica, } \\
\text { musical, corporal, espacial, naturalista, } \\
\text { interpessoal (social) ou intrapessoal } \\
\text { (individual) e existencial - só pode ser } \\
\text { desenvolvida em espaços com } \\
\text { características específicas. Necessita-se de } \\
\text { um adequado planejamento das atividades } \\
\text { para definição espacial. }\end{array}$ & $\begin{array}{l}\text { - cada inteligência linguística, lógica, musical, } \\
\text { corporal, espacial, naturalista, interpessoal (social) } \\
\text { ou intrapessoal (individual) e existencial - só pode } \\
\text { ser desenvolvida em espaços com características } \\
\text { específicas. Necessita-se de um adequado } \\
\text { planejamento das atividades para definição espacial. }\end{array}$ \\
\hline $\begin{array}{l}19 . \\
\text { lluminação } \\
\text { natural }\end{array}$ & $\begin{array}{l}\text { A iluminação natural, adequadamente } \\
\text { projetada, tem um papel fundamental na } \\
\text { qualidade do aprendizado de alunos. } \\
\text { lluminação natural pode entrar nas escolas } \\
\text { de várias maneiras (janelas, claraboias, } \\
\text { prateleiras ou túneis de luz). } \\
\text { As paredes externas também poderão ser } \\
\text { móveis para permitir a entrada de luz por } \\
\text { completo, com a integração total dos } \\
\text { espaços do interior e exterior da escola. } \\
\text { A luz natural é essencial para o bem estar } \\
\text { fisiológico e psicológico das crianças e } \\
\text { adultos, que estarão confinados, por muitas } \\
\text { horas, em espaços internos ou fechados. }\end{array}$ & $\begin{array}{l}\text { - luz natural também apoia a eficiência energética de } \\
\text { uma edificação; } \\
\text { em climas quentes, são necessários cuidados } \\
\text { especiais com a entrada de luz natural em } \\
\text { ambientes de ensino pelo ganho de calor. } \\
\text { Dispositivos de sombreamento são essenciais, } \\
\text { projetados para cada situação: latitude, clima, } \\
\text { orientação das aberturas, vegetação ou prédios } \\
\text { próximos; } \\
\text { placas fotovoltaicas devem ser incorporadas, para } \\
\text { aproveitar da energia solar no ambiente escolar. }\end{array}$ \\
\hline $\begin{array}{l}20 . \\
\text { Ventilação } \\
\text { natural }\end{array}$ & $\begin{array}{l}\text { A troca de ar frequente cria um ambiente } \\
\text { mais saudável, especialmente no caso de } \\
\text { escolas localizadas fora de áreas poluídas, } \\
\text { como centros com grande volume de } \\
\text { trânsito. } \\
\text { A ventilação natural reduz a quantidade de } \\
\text { toxinas no ar, provenientes, muitas vezes, } \\
\text { dos próprios materiais de construção; } \\
\text { também previne a formação de fungos ou } \\
\text { mofo, que podem causar sérios problemas } \\
\text { de saúde. }\end{array}$ & $\begin{array}{l}\text { - ventilação natural cruzada, projetada para todas as } \\
\text { salas de aula, laboratórios, auditórios, multiuso e } \\
\text { biblioteca; } \\
\text { - janelas livres à manipulação dos usuários para que } \\
\text { estes interfiram no próprio conforto. Janelas abertas } \\
\text { em ambientes de andares altos necessitam de } \\
\text { proteção para prevenir acidentes e quedas. }\end{array}$ \\
\hline $\begin{array}{l}21 . \\
\text { lluminação, cor } \\
\text { e } \\
\text { aprendizagem }\end{array}$ & $\begin{array}{l}\text { As características de iluminação e cor } \\
\text { devem ser pensadas de acordo com as } \\
\text { atividades a serem desenvolvidas naquele } \\
\text { espaço e não frutos de padrão estabelecido } \\
\text { ou resultado do layout inicialmente previsto. }\end{array}$ & 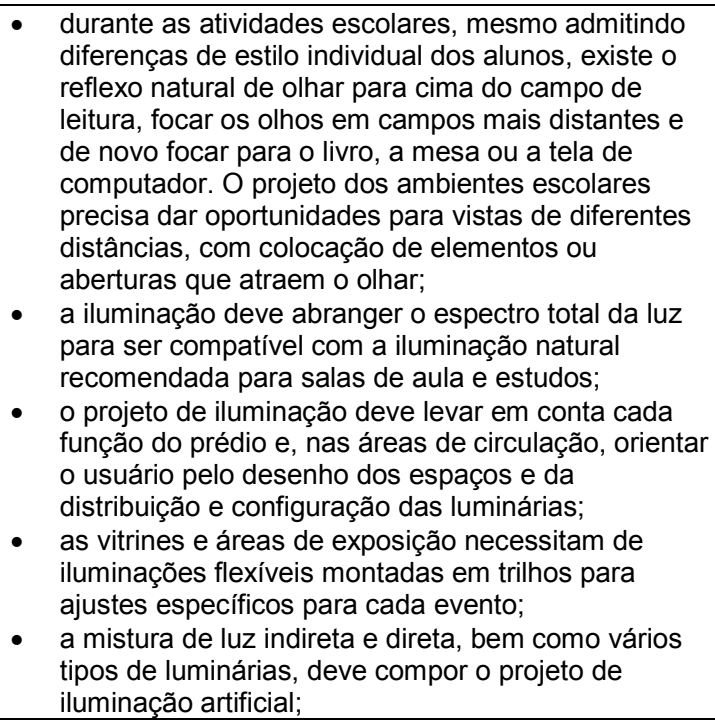 \\
\hline $\begin{array}{l}22 . \\
\text { Elementos de } \\
\text { sustenta- } \\
\text { bilidade }\end{array}$ & $\begin{array}{l}\text { Arquitetura sustentável é uma das chaves } \\
\text { para a obtenção de projetos de alto padrão } \\
\text { de desempenho. } \\
\text { O valor dessa arquitetura também deve ser } \\
\text { explorado como uma ferramenta de ensino } \\
\text { sobre a importância dessas práticas para o } \\
\text { planeta. }\end{array}$ & $\begin{array}{l}\text { - } \quad \text { abordagem que tenta minimizar os impactos da } \\
\text { construção nas características naturais do terreno; } \\
\text { - } \quad \text { os recursos energéticos da terra; } \\
\text { utilizar materiais recicláveis e que não causem } \\
\text { problemas de saúde -ela emissão de vapores } \\
\text { tóxicos; } \\
\text { - minimizar o consumo de água do edifício, } \\
\text { capturando e reutilizando água da chuva e } \\
\text { minimizando as erosões no terreno. }\end{array}$ \\
\hline 23. & A linguagem arquitetônica escolhida no & - $\quad$ a qualidade formal da arquitetura escolar é \\
\hline
\end{tabular}




\begin{tabular}{ll}
\hline \multicolumn{1}{c}{ PADRÕES } & \multicolumn{3}{c}{ IMPORTÂNCIA } \\
\hline $\begin{array}{l}\text { Assinatura } \\
\text { local }\end{array}$ & $\begin{array}{l}\text { projeto deve expressar a pedagogia e os } \\
\text { valores que a escola representa na } \\
\text { comunidade. }\end{array}$ \\
& $\begin{array}{l}\text { O edifício escolar deve estar conectado à } \\
\text { sua comunidade, através da compreensão e } \\
\text { incorporação de seus valores e desejos para } \\
\text { Conexão com } \\
\text { a comunidade }\end{array}$ \\
\hline
\end{tabular}

25. implantação a das escolas a adequação dos espaços livres
Os pátios são áreas que incorporaram, junto com as quadras esportivas todas as atividades de lazer, além das atividades pedagógicas que impliquem a necessidade de espaços externos, dada a ausência de relação destes com os espaços das salas de aula na grande maioria dos projetos escolares locais.
26. Incorporação da quadra de esportes no volume edificação
A localização da quadra de esporte para a prática de esportes e lazer é uma das principais decisões que o arquiteto precisa tomar ao enfrentar o desafio do projeto de uma edificação escolar, porque, nesse espaço, desenvolvem-se atividades conflituosas com as demais do espaço escolar.

É uma questão de segurança , em função dos problemas de violência.

27.

Fechamento da área

O ambiente escolar precisa ser seguro, tanto para a preservação de seu patrimônio físico e material, como para a segurança dos seus usuários.

28.

Integração externa entre os espaços

Discute a particularidade da integração de vários volumes implantados no lote da escola, muitas vezes com cotas de níveis diferentes, dificultando a circulação das pessoas de um bloco para o outro.

\section{9.}

Dimensiona-

mento aspectos

funcionais

de

A avaliação pós-ocupação de prédios escolares brasileiros avalia a funcionalidade baseada na análise da quantidade de área útil por aluno na sala de aula, biblioteca, laboratório, pátio e área de serviço (Ornstein; Boreli.1995).

As questões acústicas em muitas referências internacionais não indicam

30. problemas específicos em ambientes escolares, e os projetos de salas de aula sempre incluem tetos acústicos e, muitas vezes, o material do piso é de algum tipo de carpete de fácil limpeza.

Conforto

acústico

A acessibilidade está inserida na aplicação

31. dos conceitos de desenho universal

Acessibilidade requisitos fundamentais para a vivência de um individuo em um ambiente público ou privado.
DIRETRIZES DOS AMBIENTES

importante e ela própria pode se tornar um elemento que destaque a instituição em seu entorno ou, ainda, trabalhar com elementos simbólicos que exerçam essa função(jardins, fontes, elemento da história local, etc.).

- localização (próxima ao centro da comunidade);

- relação com comércio local e infraestrutura social e cultural existente;

- abertura para comunidade utilizar os espaços escolares para eventos.

- introduzir parâmetro que reflita sobre a implantação do projeto;

- o pátio coberto e as áreas livres da escola devem oferecer ambientes agradáveis, com vegetação que propicie sombra em proporção adequada aos períodos predominantes de calor do clima local;

- deve incluir um projeto paisagístico de fácil manutenção , que propicie aos usuários contato com elementos naturais e vistas humanizadas (horta, platôs interligados por rampa);

- área generosa para acomodar a espera de alunos e pais, pátio conectado à entrada para acolher alunos;

- o formato e orientação do pátio coberto devem evitar a canalização de ventos e a insolação excessiva, principalmente à tarde;

- a localização da quadra tem relação direta com as questões acústicas das salas de aula., pois as atividades são bastantes ruidosas, interferindo negativamente nos outros ambientes escolares.

- locação da quadra em terrenos de formatos e tamanhos adequados.-

- as escolas precisam fechar-se de modo adequado, mas sem se tornarem esteticamente feias ou parecidas com prisões. Algumas alternativas são muros e gradis.

- os elementos arquitetônicos e a vegetação podem ser planejados e definidos com um desenho criativo e incorporados ao projeto arquitetônico.

- dependendo da tipologia adotada pelos arquitetos , as escolas são divididas em blocos separados, mas a integração adequada é indispensável ao funcionamento da escola;

- deve-se evitar a integração sem projeto;

- os espaços devem atender às demandas mínimas de utilização (serem cobertos - dias de chuva; utilizar passarelas, etc.).

- como a área mínima recomendada por aluno $(1,5 \mathrm{~m} 2)$ costuma ser respeitada , mas rela é calculada apenas para a área da sala e a quantidade de alunos sem levar em conta os arranjos variados dos móveis para abrigar atividades diversas.

- $\quad$ as superfícies da sala de aula devem reduzir a reverberação do som, absorvendo ruído;

- no Brasil essas soluções são pouco aplicadas. As soluções focam apenas nas questões térmicas e propõem ambientes com ventilação cruzada

- $\quad$ para a equiparação nas possibilidades de uso, devese:

- $\quad$ uso de elementos arquitetônicos que permite o acesso ao ambiente para diferentes pessoas, equipamentos para circulação, prover privacidade e segurança em espaços íntimos(barras de apoio, campainhas e alarmes), instalar portas com sensores automáticos;

- inclusão das diversas formas de 


\begin{tabular}{|c|c|c|}
\hline \multirow[t]{2}{*}{ PADRÕES } & IMPORTÂNCIA & DIRETRIZES DOS AMBIENTES \\
\hline & & $\begin{array}{l}\text { comunicação(mapas táteis, pictogramas, sinalização } \\
\text { sonora, informações em Braile); } \\
\text { considerar a diversidade antropométrica ao detalhar } \\
\text { balcões, prateleiras, e mobiliário que delimitam os } \\
\text { espaços internos de uma edificação; } \\
\text { o ambiente deve ter dimensões e espaços de uso, } \\
\text { de forma a abrigar confortavelmente o usuário. }\end{array}$ \\
\hline $\begin{array}{l}32 . \\
\text { Síntese } \\
\text { padrões }\end{array}$ & $\begin{array}{l}\text { Para a verificação do atendimento de todos } \\
\text { os padrões, sugerem-se processos } \\
\text { participativos que devem definir a filosofia } \\
\text { da escola e os indicadores que o projeto } \\
\text { deverá atender. } \\
\text { Os padrões de projeto devem funcionar no } \\
\text { edifício como um todo e não isoladamente } \\
\text { considerados. }\end{array}$ & $\begin{array}{l}\text { - a qualidade do projeto de ambientes escolares e os } \\
\text { par6ametors que visam a ampliar a qualidade } \\
\text { desses ambientes para a melhoria do ensino } \\
\text { dependem também do processo de projeto, na } \\
\text { busca por soluções mais criativas e adequadas ao } \\
\text { contexto. }\end{array}$ \\
\hline
\end{tabular}

Fonte: Nair e Fielding (2005) e adaptado pelas Autoras.

Kowaltowski (2011) após análise do estudo de Nair e Fielding (2005) reconhece que, mesmo sendo uma tentativa de aproximação entre dimensões do espaço arquitetônico e suas possíveis diretrizes favoráveis ao ensino, o estudo ainda torna difícil sua tradução para a prática de projeto dado que os profissionais arquitetos se expressam numa linguagem visual.

Dessa forma, o trabalho de Nair e Fielding deve servir como ponto de partida para identificar atributos espaciais relevantes de acordo com a recorrência que venha a ser obtida na visão dos pedagogos sobre a natureza do projeto escolar.

\section{BASES CONCEITUAIS RELATIVAS DO DESEMPENHO DO ESPAÇO NO PROCESSO DE ENSINO E DE APRENDIZAGEM}

A visão de arquitetos e pedagogos sobre as possíveis relações entre características dos espaços arquitetônicos e sua influência no ensino e na aprendizagem levaram ao aprofundamento da pesquisa, quando foram identificados mais de oitenta estudos com os mais diferentes focos com predominância na área de conforto ambiental, seguido da ergonomia e da psicologia ambiental.

As relações identificadas dizem respeito a diferentes elementos constituintes desses campos disciplinares; a saber: (i) Conforto Ambiental, que se refere aos estabelecimentos escolares identificando que agentes ambientais (calor, ruído, vibrações, iluminação) que, por sua ausência, podem causar desconforto e falta de concentração, interferindo no ensino e na aprendizagem; (ii) Ergonomia, que se refere às interações entre seres humanos e outros elementos como mobiliário, cores 
equipamentos, comunicação visual e a tecnologia a fim de otimizar desempenho das atividades podendo interferir na relação ensino e aprendizagem; (iii) Psicologia Ambiental, que se refere ao conhecimento sobre a qualidade do espaço arquitetônico e sua capacidade de transmitir sensações a seus usuários, também interferindo no ensino e na aprendizagem.

O que importa para definição de um Quadro de Referência para apoiar a elaboração de um programa de necessidades é a identificação das relações relevantes para favorecer o ensino e a aprendizagem, aquelas que possam ser rapidamente ajustadas a um caso particular pela aplicação de questionários estruturados aos futuros usuários do espaço escolar em processo de projetação.

A seguir encontra-se o Quadro 2, que apresenta os principais aspectos de cada campo disciplinar estudados nessa pesquisa, e sua recorrência nas análises de diferentes autores que levaram a identificação da relevância para o ensino e a aprendizagem.

Quadro 2 - Principais características dos espaços arquitetônicos na visão de diferentes autores estudiosos das relações do espaço com a educação

\begin{tabular}{|c|c|c|c|c|c|c|c|c|c|c|c|c|}
\hline \multirow{2}{*}{$\begin{array}{c}\text { VISÕES SOBRE A RELEVÂNCIA } \\
\text { PARA A ÁREA DE ENSINO } \\
\text { Autor }\end{array}$} & \multicolumn{3}{|c|}{$\begin{array}{l}\text { CONFORTO } \\
\text { AMBIENTAL }\end{array}$} & \multicolumn{6}{|c|}{ ERGONOMIA } & \multicolumn{3}{|c|}{$\begin{array}{l}\text { PSICOLOGIA } \\
\text { AMBIENTAL }\end{array}$} \\
\hline & 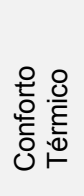 & 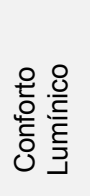 & 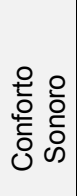 & 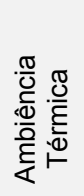 & 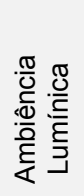 & $\begin{array}{l}\frac{\pi}{0} \\
\frac{\pi}{0} \\
\frac{0}{0} \\
\frac{0}{0} \\
\frac{1}{2} \\
\frac{1}{<}\end{array}$ & 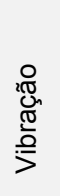 & 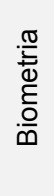 & 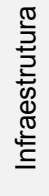 & 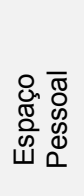 & 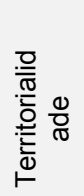 & $\begin{array}{l}\frac{0}{0} \\
\frac{\pi}{0} \\
\frac{0}{0} \\
\frac{\pi}{0} \\
\frac{1}{0} \\
0\end{array}$ \\
\hline \multicolumn{13}{|l|}{ Mueller (2007) } \\
\hline \multirow{2}{*}{\multicolumn{13}{|c|}{$\begin{array}{l}\text { Kuller e Lindsten (1992) } \\
\text { Granjean (1998) }\end{array}$}} \\
\hline & & & & & & & & & & & & \\
\hline \multicolumn{13}{|l|}{ Rio e Pires (2001) } \\
\hline \multicolumn{13}{|l|}{ Shalaway (1998) } \\
\hline \multirow{2}{*}{\multicolumn{13}{|c|}{$\begin{array}{l}\text { Beltrame e Moura (2009) } \\
\text { Oliveira \& Ribas (1995) }\end{array}$}} \\
\hline & & & & & & & & & & & & \\
\hline \multicolumn{13}{|l|}{ Silva (1996) } \\
\hline \multicolumn{13}{|l|}{ CHPS (2002) } \\
\hline \multicolumn{13}{|l|}{ Lamberts \& Xavier (2008) } \\
\hline \multicolumn{13}{|l|}{ HeschongMahone Group (1999) } \\
\hline \multicolumn{13}{|l|}{ Ruas (1999) } \\
\hline \multicolumn{13}{|l|}{ Melatti (2004) } \\
\hline \multicolumn{13}{|l|}{ EFL (Educational } \\
\hline \multirow{2}{*}{\multicolumn{13}{|c|}{$\begin{array}{l}\text { Nogueira e Durante (2005) } \\
\text { Filho et al (2007) }\end{array}$}} \\
\hline & & & & & & & & & & & & \\
\hline \multicolumn{13}{|l|}{$\begin{array}{l}\text { Filho et al (2007) } \\
\text { Mascaró (1985) }\end{array}$} \\
\hline \multicolumn{13}{|l|}{ Frota\& Schiffer (1995) } \\
\hline \multicolumn{13}{|l|}{ Seep et al. (2002) } \\
\hline \multicolumn{13}{|l|}{ Montmolin (1990) } \\
\hline \multicolumn{13}{|l|}{ Paya (1994) } \\
\hline \multicolumn{13}{|l|}{ Gravi, et alii (1985) } \\
\hline \multicolumn{13}{|l|}{ Krause et al (2005) } \\
\hline \multicolumn{13}{|l|}{ Mamede Filho (1997) } \\
\hline \multicolumn{13}{|l|}{ Abadié et al.(2009) } \\
\hline \multicolumn{13}{|l|}{ Ribeiro (2004) } \\
\hline Randon (2007) & & & & & & & & & & & & \\
\hline
\end{tabular}




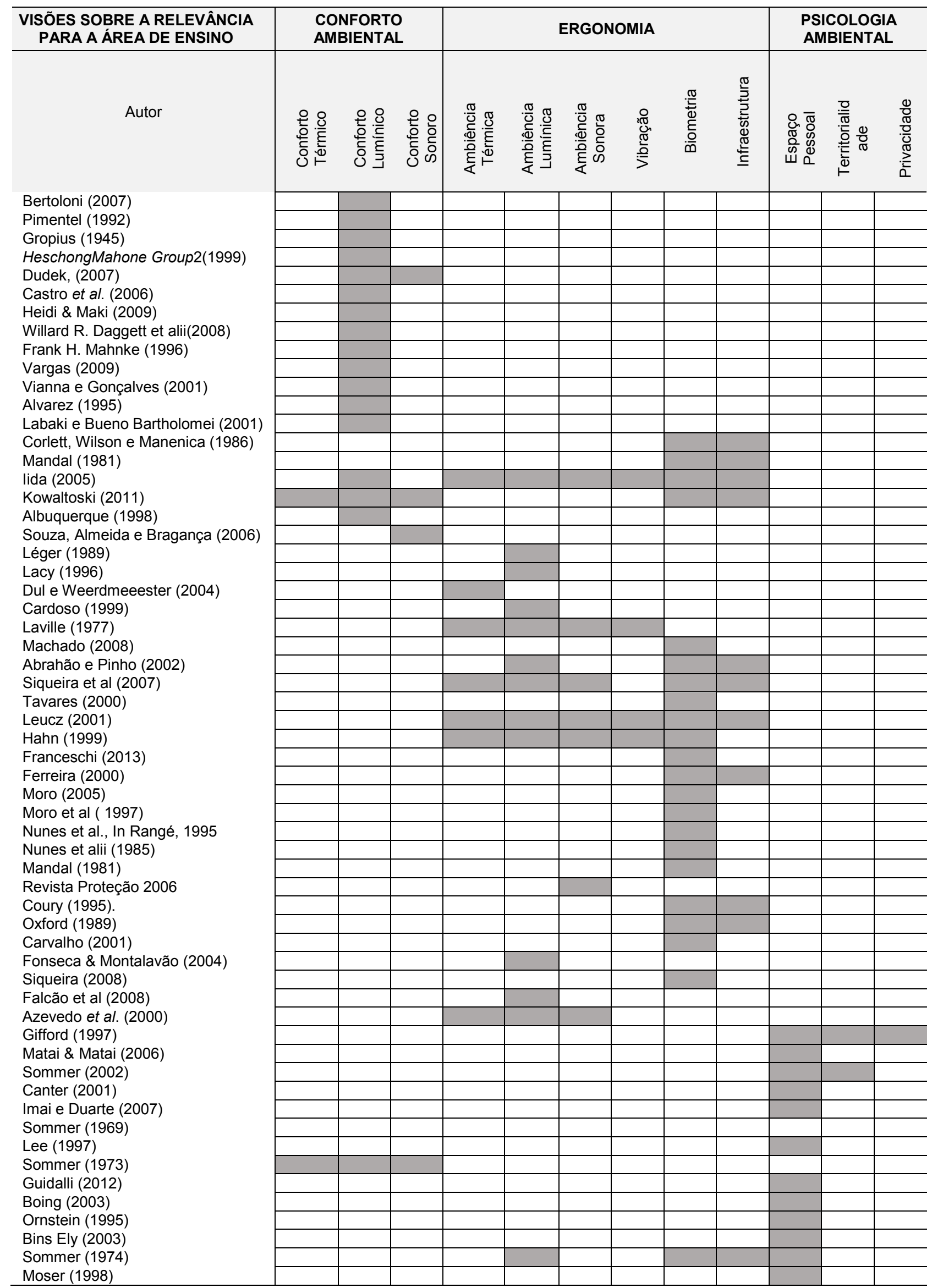

Fonte: Elaborado pelas autoras (2016). 


\section{ANÁLISE DOS DADOS: ATRIBUTOS ESPACIAIS PARA APOIO A PROJETOS ARQUITETÔNICOS DE ESCOLAS}

A ampla base de dados obtida na pesquisa após a análise de recorrência e de relevância resultou na proposição de um quadro referencial composto de 11 atributos e 32 padrões, distribuídos nos 3 campos disciplinares conforme Quadro 3. A nomenclatura utilizada foi definida de modo a apoiar futuros questionários de ajuste e validação para casos concretos, com a definição de conceitos e a forma como cada atributo impacta de forma positiva o ensino e o aprendizado.

O mais relevante, ainda, foi o esforço realizado no sentido de estabelecer a forma de como configurar cada padrão de modo a dialogar com a linguagem típica dos projetos de arquitetura. 
Quadro 3 - Atributos e padrões do espaço arquitetônico necessários ao programa de necessidades para elaboração de projeto de arquitetura para escolas

\begin{tabular}{|c|c|c|c|c|}
\hline CATEGORIA & CONCEITO & ATRIBUTO & PADRÕES & COMO SE CONFIGURAM \\
\hline \multirow{10}{*}{ Conforto Ambiental } & \multirow{10}{*}{ 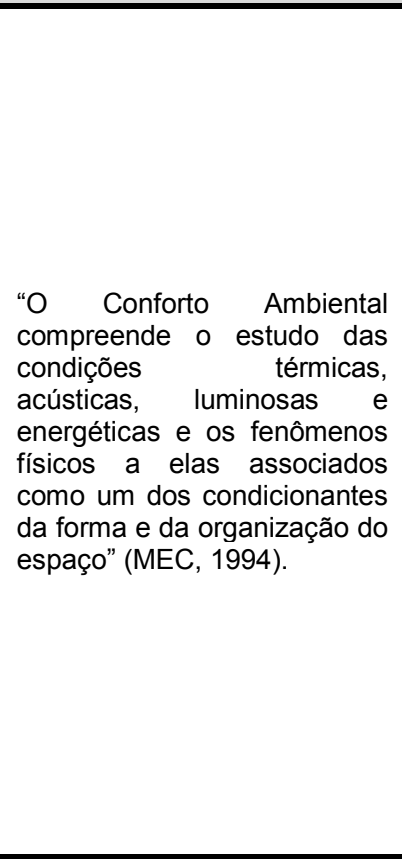 } & \multirow{5}{*}{$\begin{array}{l}\text { Conforto } \\
\text { Térmico }\end{array}$} & Ventilação & $\begin{array}{l}\text { os movimentos de ar aceleram as trocas de calor das pessoas com o ambiente por } \\
\text { convecção por evaporação. }\end{array}$ \\
\hline & & & $\begin{array}{l}\text { Resfriamento } \\
\text { evaporativo }\end{array}$ & $\begin{array}{l}\text { consiste na redução da temperatura do ambiente por meio da evaporação de micro } \\
\text { gotículas de água aspergidas - ou borrifadas - no ar e espalhadas no ambiente por } \\
\text { ventiladores de alto desempenho. }\end{array}$ \\
\hline & & & $\begin{array}{l}\text { Massa Térmica para } \\
\text { Aquecimento }\end{array}$ & $\begin{array}{l}\text { é uma solução empregável em locais nos quais as temperaturas e umidade relativas } \\
\text { estejam entre determinados valores. Essa estratégia permite que o calor } \\
\text { armazenado na estrutura térmica durante o dia seja devolvido à noite, quando as } \\
\text { temperaturas externas diminuem. }\end{array}$ \\
\hline & & & Umidificação & $\begin{array}{l}\text { introdução de vapor de água no ar para a obtenção da umidade desejada. É a } \\
\text { quantidade de vapor de água na atmosfera. }\end{array}$ \\
\hline & & & Ar condicionado & aparelhos destinados ao condicionamento do ar. \\
\hline & & \multirow{3}{*}{$\begin{array}{l}\text { Conforto } \\
\text { Luminoso }\end{array}$} & $\begin{array}{l}\text { Mecanismos de } \\
\text { Controle }\end{array}$ & $\begin{array}{l}\text { a luz do sol pode ser manipulada através do uso de uma série de mecanismos como } \\
\text { reflexão, transmissão, refração, polarização, absorção, difusão, dentre outros. }\end{array}$ \\
\hline & & & $\begin{array}{l}\text { Reforço } \\
\text { Iluminamento }\end{array}$ & $\begin{array}{l}\text { a iluminação artificial feita por lâmpadas elétricas é um reforço à iluminação natural e } \\
\text { pode ser geral, ilumina todo o ambiente ou suplementar, ilumina melhor um } \\
\text { determinado objeto ou ação e complementa a iluminação geral. }\end{array}$ \\
\hline & & & Uso das cores & $\begin{array}{l}\text { Cor é uma percepção visual provocada pela ação de um feixe de fótons sobre } \\
\text { células especializadas da retina, que transmitem através de informação pré- } \\
\text { processada ao nervo ótico, impressões para o sistema nervoso. }\end{array}$ \\
\hline & & \multirow{2}{*}{$\begin{array}{l}\text { Conforto } \\
\text { Acústico }\end{array}$} & $\begin{array}{l}\text { Tempo de } \\
\text { reverberação }\end{array}$ & $\begin{array}{l}\text { é o período necessário para a energia sonora decair de um milhão de vezes em } \\
\text { relação a sua energia inicial, isto é, o tempo necessário para o nível em decibéis } \\
\text { decair em } 60 \mathrm{~dB} \text { e expressa a capacidade de absorção do ambiente. }\end{array}$ \\
\hline & & & Isolamento Sonoro & $\begin{array}{l}\text { melhor qualidade sonora para o interior e controle do ruído de fora para dentro dos } \\
\text { ambientes. }\end{array}$ \\
\hline \multirow{5}{*}{ Ergonomia } & \multirow{5}{*}{$\begin{array}{l}\text { "Ergonomia (ou Fatores } \\
\text { Humanos) é a disciplina } \\
\text { cientifica que estuda as } \\
\text { interações entre os seres } \\
\text { humanos e outros elementos } \\
\text { do sistema, e a profissão que } \\
\text { aplica teorias, princípios, } \\
\text { dados e método, a projetos } \\
\text { que visem otimizar o bem- } \\
\text { estar humano e o o } \\
\text { desempenho global de } \\
\text { sistemas" (IEA, 2009). }\end{array}$} & \multirow{4}{*}{$\begin{array}{l}\text { Ambiência } \\
\text { Térmica }\end{array}$} & Temperatura & $\begin{array}{l}\text { a temperatura do ar afeta a perda de calor convectivo do corpo do homem e a } \\
\text { temperatura do ar expirado por ele. Assim, a perda de calor pelo aquecimento e } \\
\text { umidificação do ar expirado é influenciada pela temperatura do ar. }\end{array}$ \\
\hline & & & $\begin{array}{l}\text { Velocidade de } \\
\text { deslocamento do } \mathrm{Ar}\end{array}$ & $\begin{array}{l}\text { determinante na troca de calor por convecção entre o corpo e meio ambiente. } \\
\text { Quanto mais intensa for a ventilação, maior será a quantidade de calor trocada entre } \\
\text { o corpo humano e } \\
\text { o ar, consequentemente menor será a sensação de calor. }\end{array}$ \\
\hline & & & Umidade & $\begin{array}{l}\text { a umidade do ar é um fator que interfere diretamente em três mecanismos de perda } \\
\text { de água do corpo humano: a difusão de vapor d'água através da pele (transpiração } \\
\text { imperceptível), a evaporação do suor da pele e a umidificação do ar respirado. }\end{array}$ \\
\hline & & & $\begin{array}{l}\text { Radiação } \\
\text { Infravermelha }\end{array}$ & $\begin{array}{l}\text { o corpo humano troca calor continuamente com o ambiente, por radiação, } \\
\text { recebendo calor de objetos mais quentes e irradiando para os mais frios que o seu } \\
\text { corpo. }\end{array}$ \\
\hline & & $\begin{array}{r}\text { Ambiência } \\
\text { Lumínica }\end{array}$ & lluminação & $\begin{array}{l}\text { é a quantidade de luz natural ou artificial no nível da situação de trabalho. Uma } \\
\text { iluminação incorreta induz à fadiga, ao desconforto. }\end{array}$ \\
\hline
\end{tabular}

R. Inter. Interdisc. INTERthesis, Florianópolis, v.13, n.2, p.58-75 Mai-Ago. 2016 


\section{CATEGORIA}

PADRÕES

\section{COMO SE CONFIGURAM}

é a quantidade de luz refletida que entra no olho e estimula a retina. Muita luz causa ofuscamento, pouca luz causa percepção ruim ou impossível. É o fluxo luminoso incidente por unidade de area iluminada.

\begin{tabular}{|c|c|c|}
\hline & Luminância & $\begin{array}{l}\text { ofuscamento, pouca luz causa percepção ruim ou impossível. É o fluxo luminoso } \\
\text { incidente por unidade de área iluminada. }\end{array}$ \\
\hline & Contraste & é a relação de iluminância entre o objeto observado e os que os cercam. \\
\hline \multirow{3}{*}{$\begin{array}{l}\text { Ambiência } \\
\text { Sonora }\end{array}$} & Nível sonoro & $\begin{array}{l}\text { relaciona a intensidade sonora de um som com a intensidade sonora do som mais } \\
\text { fraco. que conseguimos ouvir. }\end{array}$ \\
\hline & Frequência & $\begin{array}{l}\text { número de variações de pressão (ou de oscilações) durante um segundo. A unidade } \\
\text { de frequência é o Hertz, Hz. }\end{array}$ \\
\hline & $\begin{array}{l}\text { Duração } \\
\text { exposição }\end{array}$ & tempo da exposição diária ao ruído durante o trabalho. \\
\hline \multirow[t]{2}{*}{ Vibrações } & Frequência & $\begin{array}{l}\text { expressa quantas vezes na unidade de tempo, o ciclo da vibração se produziu, ou } \\
\text { seja é a quantidade de vezes em que um sinal se repete a cada segundo. }\end{array}$ \\
\hline & Intensidade & ampliação ou atenuação das vibrações. \\
\hline \multirow{2}{*}{ Biometria } & Arranjo Físico & $\begin{array}{l}\text { o layout de um espaço de trabalho consiste na proposta de distribuição espacial de } \\
\text { um conjunto de trabalhadores, equipamentos, infraestrutura e materiais. }\end{array}$ \\
\hline & Mobiliário & $\begin{array}{l}\text { é notadamente um elemento da sala de aula que influi circunstancialmente no } \\
\text { desempenho, segurança, conforto e em diversos comportamentos dos alunos. }\end{array}$ \\
\hline \multirow{4}{*}{ Infraestrutura } & Revestimentos & $\begin{array}{l}\text { pode-se adotar posturas distintas, em função do uso do ambiente e da atividade } \\
\text { desenvolvida. Alguns setores produtivos apresentam normatizações quanto ao } \\
\text { emprego dos materiais. }\end{array}$ \\
\hline & Cores & $\begin{array}{l}\text { a cor no local de trabalho pode aumentar o humor e a produtividade do indivíduo ao } \\
\text { gerar sensações de conforto, dinamismo e bem estar. }\end{array}$ \\
\hline & Equipamentos & $\begin{array}{l}\text { Diversas tecnologias novas têm sido introduzidas na educação, como uso de } \\
\text { materiais áudios visuais, vídeos. . }\end{array}$ \\
\hline & Ambiente Físico & $\begin{array}{l}\text { o projeto adequado dos mobiliários, salas de aula, bibliotecas, laboratórios, e outros } \\
\text { meios de apoio didático, podem influir no desempenho dos professores e alunos. }\end{array}$ \\
\hline \multirow{3}{*}{$\begin{array}{l}\text { Espaço } \\
\text { pessoal }\end{array}$} & $\begin{array}{l}\text { Distâncias } \\
\text { interpessoais }\end{array}$ & $\begin{array}{l}\text { referem-se às distâncias adequadas para contato ou não-contato podendo gerar } \\
\text { reações comportamentais positivas ou negativas. }\end{array}$ \\
\hline & $\begin{array}{l}\text { Relações } \\
\text { Interpessoais }\end{array}$ & $\begin{array}{l}\text { relação entre duas ou mais pessoas. Este tipo de relacionamento é marcado pelo } \\
\text { contexto onde ele está inserido, podendo ser um contexto familiar, escolar, de } \\
\text { trabalho ou de comunidade. }\end{array}$ \\
\hline & $\begin{array}{l}\text { Configuração } \\
\text { Ambiental (Design) }\end{array}$ & $\begin{array}{l}\text { as configurações de arranjo físico sociopetal (o que possibilita o contato social) e } \\
\text { sociofugal (o que não propicia o contato social) influenciam o espaço pessoal, e sua } \\
\text { qualificação depende da cultura dos usuários e da situação ou função a que se } \\
\text { destina o ambiente. }\end{array}$ \\
\hline \multirow{3}{*}{$\begin{array}{l}\text { Territo- } \\
\text { rialidade }\end{array}$} & Ocupação & controle efetivo de um espaço ou de alguma coisa. \\
\hline & Defesa & $\begin{array}{l}\text { O espaço defesível argumenta que os arranjos físicos aumentam sentimentos de } \\
\text { territorialidade e comportamentos, e que esse aunento conduz a um declínio nas } \\
\text { invasões do território. }\end{array}$ \\
\hline & Personalização & marcação de uma maneira que indica uma identidade. \\
\hline $\begin{array}{l}\text { Privaci- } \\
\text { dade }\end{array}$ & Privacidade & $\begin{array}{l}\text { é a gestão do indivíduo sobre as informações de si mesmo e sobre a sua interação } \\
\text { com as outras pessoas. É um controle seletivo de acesso a si próprio ou ao grupo }\end{array}$ \\
\hline
\end{tabular}

Psicologia Ambiental é o

estudo da transação entre

indivíduos e o cenário físico.

Nestas transações, indivíduos

modificam o ambiente e seu pelo ambiente experiências são modificados

modificam o ambiente e seu
comportamento
experiências são modificados
pelo ambiente

R. Inter. Interdisc. INTERthesis, Florianópolis, v.13, n.2, p.58-75 Mai-Ago. 2016 


\section{RESULTADOS E DESDOBRAMENTOS DA PESQUISA}

A contribuição que a pesquisa trouxe ao tema reforça a premissa que o espaço arquitetônico pode colaborar para um melhor desempenho das funções de ensino e aprendizagem avançando na definição de atributos espaciais passíveis de parametrização possibilitando que sua inserção na definição do programa de necessidades para atender a elaboração de projetos arquitetônicos.

Como referido ao longo do trabalho, grande parte dos estudos consultados se debruçam no ensino infantil, o que elevou a pesquisa a estabelecer um recorte de relevância sobre os aspectos que eram válidos para todos os tipos de públicos com vistas a focar em referências que pudessem ser utilizadas nos espaços universitários, onde certamente o campo do conforto ambiental se destacou a forma de ajuste a realidade de cada contexto de curso na universidade, deve ser realizada por meio de questionários a serem aplicados ao corpo docente e discente para validar e ajustar o Quadro de Referência proposto. Nesse sentido, já foi elaborado um modelo de questionário estruturado, utilizando técnicas de análise multicritério, onde são listados atributos e conceitos em discussão para identificar a relevância para contextos de ambientes de ensino diferenciados.

A título de um exercício de validação a pesquisa de campo foi aplicada na Faculdade de Arquitetura e Urbanismo da Universidade de Brasília que está passando por uma requalificação de seu espaço físico, o universo foi o conjunto dos 65 professores com $60 \%$ de respostas.

Esse passo da pesquisa está consoante com o entendimento de que a aplicação dos padrões para o ambiente universitário, apoiando a elaboração do seu projeto arquitetônico, deve ocorrer como função do campo disciplinar, das metodologias de ensino e de suas tecnologias.

R. Inter. Interdisc. INTERthesis, Florianópolis, v.13, n.2, p.58-75 Mai-Ago. 2016 


\title{
ARCHITECTURAL SPACE CHARACTERISTICS FACILITATING TEACHING AND APPRENTICESHIP
}

\begin{abstract}
:
The article discusses the relevance of the architectural space as a facilitator of teaching and learning processes. It adopts an analytical methodology based on the architecture and pedagogy literature to know the view of these areas on the subject, and identifies relevant spatial attributes to facilitate education. Research has shown that there are recurrences pointing disciplinary fields of environmental comfort, ergonomics and environmental psychology, which were the subject of this conceptual research about the positive and negative impacts on the school design facility by each attribute of these disciplines. As result, it presents a framework of attributes, characteristics and relevance to teaching and learning to be used as support to the space needs assessment, ie: during the first stage of an architectural design process. Keywords: Architecture. Apprenticeship. Project. School. Space.
\end{abstract}

\section{CARACTERÍSTICAS DEL ESPACIO ARQUITECTÓNICO QUE FACILITEN LA ENSEÑANZA Y EL APRENDIZAJE}

\section{Resumen:}

El artículo aborda la importancia del espacio arquitectónico como facilitador del proceso de enseñanza y aprendizaje. Utiliza la metodología analítica fundamentada en la investigación bibliográfica para conocer el punto de vista de los ámbitos de la arquitectura y la pedagogía sobre el tema, e identificar los atributos espaciales pertinentes para facilitar la educación. La investigación ha demostrado que hay recurrencias apuntando los campos disciplinarios de confort ambiental, ergonomía y psicología ambiental, los cuales han sido objeto de esta investigación conceptual sobre los impactos positivos y negativos de cada atributo de estas disciplinas en las instalaciones de la escuela. Como resultado se presenta una Tabla de Referencias de atributos, sus posibilidades en cuanto espacio y la relevancia para la enseñanza y el aprendizaje que se utilizarán para apoyar la formulación de programas de necesidades arquitectónicas, es decir: en la primera etapa de la preparación de un proceso de proyecto arquitectura.

Palabras clave: Aprendizaje. Arquitectura. Escuela. Espacio. Proyecto. 


\section{REFERÊNCIAS}

ALEXANDER Christopher et ali. A Pattern Language. Oxford University Press, 1977.

ALEXANDER, Christopher. A Timeless Way of Building. Oxford University Press, 1979.

BUFFA, Ester; ALMEIDA PINTO, Gelson. Arquitetura e Educação: Organização do Espaço e Propostas Pedagógicas dos Grupos Escolares Paulistas, 1893/1971. São Carlos: EDUFSCar/INEP, 2002.

COSTA, Lúcio. Opção, recomendações e recado; In: Lúcio Costa: Registro de uma vivência. São Paulo, Empresa das Artes, 1995, p. 382.

KOWALTOWSKI, Dóris. Arquitetura escolar: o projeto do ambiente de ensino.

Oficina de Textos, $1^{\text {a }}$ ed. São Paulo, SP, 2011.

MCDONALD, Joseph P. Redesigning school: lessons for the 21st.century. São Francisco: Jossey-Bass, 1996.

NAIR, Parkash; FIELDING, Randall. The language of school design. Design patterns for the 21th Century School. $2^{\text {a }}$ ed. National Clearinghouse for Educational Facilities. India, 2005.

PAULY, Edward. The classroom crucible: what really works, what doesn't, and why. New York: Basic books, 1991.

SOHIA, Paulo. A construção da surpresa, Revista Educação, seção entrevistas/dossiê, setembro de 2011. Disponível em: <http://revistaeducacao.com.br/textos/128/artigo234299-1.asp>.

TEIXEIRA, Anísio. Pensamento e ação. Civilização Brasileira, Rio de Janeiro 1960.

Artigo

Recebido em 26 de Agosto de 2015

Aceito em 23 de Maio de 2016

R. Inter. Interdisc. INTERthesis, Florianópolis, v.13, n.2, p.58-75 Mai-Ago. 2016 